\title{
Características analíticas de vinhos Chardonnay da Serra Gaúcha
}

\author{
Analytical characteristcs of Chardonnay wines from the Serra Gaúcha region
}

\author{
Luiz Antenor Rizzon ${ }^{\mathrm{I} *}$ Alberto Miele ${ }^{\mathrm{I}}$ Giseli Scopel ${ }^{\mathrm{II}}$
}

\begin{abstract}
A uva 'Chardonnay' é uma cultivar originária da RESUMO região da Borgonha, França. Na Serra Gaúcha, RS, ela adquiriu notoriedade em razão da produção de vinho branco varietal e da sua utilização como base para espumante. $\mathrm{Na}$ safra de 2007, representou 6,3\% do total das uvas brancas viníferas processadas. Em vista disso, este trabalho foi realizado com o objetivo de avaliar a composição físico-química do vinho Chardonnay elaborado na Serra Gaúcha, visando à formação de um banco de dados, à determinação de sua identidade varietal e a sua caracterização regional. Analisaramse 125 vinhos, safras 1998 a 2005, de 28 vinícolas. As análises foram realizadas na Embrapa Uva e Vinho, em Bento Gonçalves, RS. As determinações clássicas foram efetuadas por meio de métodos físico-químicos; os compostos voláteis, por cromatografia gasosa; e os elementos minerais, com exceção do $P$, por espectrofotometria de absorção atômica. Os resultados mostram que o vinho Chardonnay enquadrou-se nos limites estabelecidos pela legislação brasileira. Observaram-se valores elevados de álcool, extrato seco reduzido, cinzas, prolina e $K$, variáveis que garantem boa estrutura e corpo ao vinho branco; e teores baixos de compostos voláteis, especialmente de álcoois superiores, que favorecem os aromas frutados e florais.
\end{abstract}

Palavras-chave: vinho, composição, caracterização.

\section{ABSTRACT}

'Chardonnay' is a grapevine cultivar which origin is in the Burgundy region, France. It acquired economic importance in the Serra Gaúcha viticultural area, Brazil, due to the production of varietal white wine and sparkling wine. In 2007 it represented $6.3 \%$ of the total vinifera white grapes processed. Because of its importance to the wine industry, the physicochemical composition of Chardonnay wine from the
Serra Gaúcha was evaluated to develop a databank and to establish its varietal identity and regional characterization. Chardonnay wines - 125 samples - from the 1998 to 2003 vintages, made by 28 wineries, were analyzed. Analyses were performed in the Embrapa Grape and Wine Research Center, located in Bento Gonçalves, RS. Classical variables were performed by physicochemical methods; volatile compounds by gas chromatography; and mineral elements by atomic absorption spectrophotometry, exception to P. Results showed that Chardonnay wines had parameters according to the Brazilian legislation. High values of the following variables were observed: alcohol, reduced dry extract, ashes, proline, and $K$, which are responsible for the structure and body of white wine; and low values of volatile compounds, especially those related to the higher alcohols, responsible for fruity and floral wine aromas.

Key words: wine, composition, characterization.

A cultivar 'Chardonnay’ é originária da região da Borgonha, França, responsável pela qualidade dos vinhos brancos elaborados nessa região, a qual é difundida em várias áreas vitícolas do mundo (WOLPERT et al., 1994; FIDELIBUS et al., 2006; ANDERSON et al., 2008). Além disso, juntamente com a Pinot Noir e com a Pinot Meunier, compõe a estrutura varietal do champanhe. Embora essa cultivar tenha sido introduzida no Brasil na década de 1930, na região de São Roque, em São Paulo, e no Rio Grande do Sul, por volta de 1948, foi somente na década de 1980 que ela adquiriu notoriedade na Serra Gaúcha, por meio da produção de vinho branco fino e sua utilização como

'Embrapa Uva e Vinho, 95700-000, Bento Gonçalves, RS, Brasil. E-mail: rizzon@cnpuv.embrapa.br. *Autor para correspondência.

"Vinícola Perini Ltda., Farroupilha, RS, Brasil. 
base para espumante. Nas últimas 10 safras, a quantidade de uva Chardonnay processada no Rio Grande do Sul passou de 2.966,7t em 1998 a 1.752,5t em 2007, representando, respectivamente, 9,2\% e 6,3\% do total de uvas viníferas brancas processadas (UVIBRA, 2008).

Tendo em vista a participação da uva Chardonnay na qualidade do vinho branco fino e do espumante da Serra Gaúcha e a pouca disponibilidade de informação sobre o assunto, realizou-se o presente trabalho com o objetivo de avaliar a composição físicoquímica desse vinho varietal, visando a formar um banco de dados e a estabelecer sua identidade varietal e caracterização da tipicidade regional. Analisaram-se 125 vinhos varietais Chardonnay provenientes de 28 vinícolas da Serra Gaúcha elaborados de 1998 a 2005. As análises foram realizadas nos laboratórios de Enoquímica e de Instrumentação da Embrapa Uva e Vinho, em Bento Gonçalves, RS.

As determinações físico-químicas foram efetuadas segundo metodologia descrita por AMERINE \& OUGH (1976); os minerais, por espectrofotometria de absorção atômica, utilizando um espectrofotômetro Perkin Elmer, modelo 2380 (PERKIN ELMER, 2000); o P foi determinado por colorimetria, usando o molibdato de amônio (RIBÉREAU-GAYON et al., 1982); os compostos voláteis, por cromatografia gasosa (BERTRAND, 1975). Para cada variável, calcularam-se o intervalo de confiança, a média e o coeficiente de variação.

Os resultados das análises clássicas, dos compostos voláteis e dos minerais são mostrados na tabela 1. Eles indicam que os vinhos Chardonnay avaliados enquadraram-se nos padrões de identidade e qualidade estabelecidos pelo Ministério da Agricultura, Pecuária e Abastecimento para vinhos brancos finos secos (BRASIL, 1998) e nas normas do MERCOSUL (2002). Dentre as análises efetuadas, o álcool aparece em concentração relativamente elevada, considerando vinhos brancos finos nacionais, mesmo estando abaixo do teor máximo estabelecido pela legislação brasileira (BRASIL, 1998). Ele é uma consequência da maturação da uva, ainda que a chaptalização seja uma prática enológica permitida. Detectaram-se valores baixos de acidez volátil e elevados da D.O. 420, provavelmente em consequência do início do processo oxidativo e/ou do amadurecimento do vinho em barricas de carvalho. Da mesma forma, a acidez titulável foi baixa, e o pH levemente elevado, variáveis que estão relacionadas negativamente com o frescor do vinho branco. Isso pode ter sido devido à maturação da uva e/ou à realização da fermentação malolática dos vinhos.
Quanto ao extrato seco, extrato seco reduzido e cinzas, os teores detectados atribuem estrutura ao vinho Chardonnay, característica que o diferencia dos vinhos brancos de outras cultivares, geralmente menos estruturados. A alcalinidade das cinzas apresentou valor considerado baixo, evidenciando que o ácido tartárico encontrava-se mais na forma livre, realçando o gosto ácido. A concentração de prolina foi elevada em comparação a de outros vinhos varietais (RIZZON et al., 1993). Os valores de glicerol situaram-se nos limites indicados, que variaram entre $10 \%$ e $15 \%$ do peso do etanol (RIBÉREAU-GAYON et al., 1998), participando do extrato seco e, consequentemente, da estrutura do vinho. As concentrações das substâncias voláteis foram relativamente baixas, o que é um aspecto positivo para a sua qualidade. Embora formados por um grande número de compostos químicos, eles representam somente $1 \%$ do peso do etanol e apenas seis deles participam com mais de $50 \%$ do peso total dos compostos voláteis (RIBÉREAU-GAYON et al., 1998). Concentrações elevadas de aldeído acético transmitem gosto e aroma de oxidação ao vinho. O acetato de etila é responsável por aroma e gosto acéticos, e os álcoois superiores interferem na formação de aroma e gosto herbáceos e sem fineza quando presentes em concentrações superiores a $250 \mathrm{mg} \mathrm{L}^{-1}$ (BERTRAND, 1975). De modo geral, os vinhos avaliados apresentaram teores de metanol nos níveis encontrados em outros varietais brancos finos da Serra Gaúcha (RIZZON, 1987). O teor desse álcool no vinho está relacionado principalmente com o sistema de vinificação adotado, especialmente no que se refere à maceração pelicular e à forma de extração do mosto (RIBÉREAU-GAYON et al., 1998).

Os elementos minerais dos vinhos constituem as cinzas, que representaram 10,9\% do extrato seco reduzido. A legislação brasileira estabelece teor mínimo de cinzas de $1,0 \mathrm{~g} \mathrm{~L}^{-1}$ para o vinho branco fino (BRASIL, 1998). Entre os elementos minerais analisados, o $\mathrm{K}$ é o que se encontrou em maior proporção, pois, neste trabalho, sua participação foi de 33,7\% das cinzas. Esse cátion interfere também na acidez do vinho, por meio da salificação do ácido tartárico. O vinho Chardonnay caracterizou-se por apresentar teores elevados de minerais em comparação com os demais vinhos brancos finos da Serra Gaúcha (RIZZON et al., 2008). O teor de Na depende dos produtos enológicos utilizados na vinificação; e os de Ca e de Mg podem estar relacionados com a composição do solo, o programa de adubação e a eventual presença na uva desses minerais em razão da aplicação de calda bordalesa no controle de doenças fúngicas. A concentração de $\mathrm{Fe}, \mathrm{Cu}$ e $\mathrm{Zn}$ é influenciada pela 
Tabela 1 - Características analíticas de vinhos Chardonnay da Serra Gaúcha.

\begin{tabular}{|c|c|c|c|c|}
\hline Variável & Intervalo de & confiança* & Média & $\mathrm{CV}(\%)$ \\
\hline \multicolumn{5}{|l|}{ Análises clássicas } \\
\hline Densidade a $20 / 20^{\circ} \mathrm{C}\left(\mathrm{g} \mathrm{mL}^{-1}\right)$ & 0,9925 & - 0,9930 & 0,9927 & 0,1 \\
\hline Álcool (\% v/v) & 11,87 & $-12,20$ & 12,03 & 5,7 \\
\hline Acidez titulável (meq L ${ }^{-1}$ ) & 69,3 & $-75,6$ & 72,4 & 18,1 \\
\hline Acidez volátil (meq $\mathrm{L}^{-1}$ ) & 6,5 & $-7,6$ & 7,0 & 31,4 \\
\hline $\mathrm{pH}$ & 3,37 & $-3,46$ & 3,42 & 5,3 \\
\hline Extrato seco $\left(\mathrm{g} \mathrm{L}^{-1}\right)$ & 18,41 & $-19,71$ & 19,06 & 14,2 \\
\hline Açúcares redutores (g L $\left.{ }^{-1}\right)$ & 1,91 & $-2,27$ & 2,09 & 35,9 \\
\hline Extrato seco reduzido $\left(\mathrm{g} \mathrm{L}^{-1}\right)$ & 17,40 & - 18,77 & 18,09 & 15,6 \\
\hline Relação álcool em peso/Extrato seco reduzido & 5,25 & $-5,60$ & 5,43 & 13,6 \\
\hline Cinzas $\left(\mathrm{g} \mathrm{L}^{-1}\right)$ & 1,97 & $-2,20$ & 2,09 & 23,0 \\
\hline Alcalinidade das cinzas (meq L ${ }^{-1}$ ) & 19,12 & $-21,44$ & 20,28 & 23,7 \\
\hline D.O. 420nm & 0,125 & - 0,161 & 0,143 & 51,0 \\
\hline Prolina (mg L $\left.{ }^{-1}\right)$ & 433 & -968 & 701 & 157 \\
\hline Glicerol ( $\left.\mathrm{g} \mathrm{L}^{-1}\right)$ & 8,8 & $-10,8$ & 9,8 & 29,6 \\
\hline Dióxido de enxofre total (mg L $\left.{ }^{-1}\right)$ & 83 & -98 & 91 & 34,3 \\
\hline \multicolumn{5}{|l|}{ Compostos voláteis (mg L $\left.{ }^{-1}\right)$} \\
\hline Aldeído acético & 41,4 & - 55,4 & 48,4 & 62,4 \\
\hline Acetato de etila & 49,2 & $-98,2$ & 73,7 & 144,1 \\
\hline Metanol & 54,5 & - 64,0 & 59,2 & 34,6 \\
\hline 1-Propanol & 30,5 & $-35,9$ & 33,2 & 35,5 \\
\hline 2-Metil-1-propanol & 26,1 & $-32,0$ & 29,1 & 44,3 \\
\hline 2-Metil-1-butanol+3-metil-1-butanol & 151,4 & $-168,4$ & 159,9 & 23,1 \\
\hline Soma dos álcoois superiores & 212,7 & $-231,7$ & 222,2 & 18,6 \\
\hline \multicolumn{5}{|l|}{ Minerais (mg L ${ }^{-1}$ ) } \\
\hline K & 641 & -768 & 705 & 30,3 \\
\hline $\mathrm{Na}$ & 24,8 & $-39,2$ & 32,0 & 75,3 \\
\hline $\mathrm{Ca}$ & 81,4 & $-91,8$ & 86,6 & 20,2 \\
\hline $\mathrm{Mg}$ & 74,3 & - 79,8 & 77,0 & 12,0 \\
\hline $\mathrm{Mn}$ & 2,6 & $-3,0$ & 2,8 & 25,0 \\
\hline $\mathrm{Fe}$ & 1,7 & $-2,3$ & 2,0 & 50,0 \\
\hline $\mathrm{Cu}$ & 0,12 & $-0,24$ & 0,18 & 105,6 \\
\hline $\mathrm{Zn}$ & 0,55 & - 0,70 & 0,63 & 38,1 \\
\hline $\mathrm{Rb}$ & 3,8 & $-4,5$ & 4,1 & 26,8 \\
\hline $\mathrm{P}$ & 83,6 & $-100,2$ & 91,9 & 30,5 \\
\hline
\end{tabular}

*Nível de probabilidade de erro do intervalo de confiança a $1 \%$.

eventual presença desses minerais na uva ou então liberados por meio do contato com recipientes e equipamentos utilizados no processo de elaboração do vinho. Teores baixos desses elementos são necessários para garantir sua estabilidade. O Rb é encontrado naturalmente em todos os vinhos, em quantidades reduzidas, que variam de 1,0 a $10,0 \mathrm{mg} \mathrm{L}^{-1}$, e sua presença pode estar relacionada à origem geográfica destes. Nesse sentido, detectou-se concentração mais elevada de Rb no vinho Chardonnay da Serra Gaúcha em comparação aos argentinos e uruguaios (RIZZON et al., 1997). A concentração de $P$ está relacionada com sua presença na uva, a utilização de sais de fosfato de amônio como ativadores das leveduras na fermentação alcoólica e a intensidade de prensagem da uva (RIBÉREAU-GAYON et al., 1998). A concentração de P detectada no vinho Chardonnay se equivale à encontrada em outros vinhos brancos finos da Serra Gaúcha.

Em conclusão, os resultados mostram que o vinho Chardonnay da Serra Gaúcha caracteriza-se por apresentar teores relativamente elevados de álcool, 
extrato seco reduzido, cinzas, prolina e K, variáveis que atribuem estrutura e corpo ao vinho, e baixos de compostos voláteis, especialmente de álcoois superiores, que determinam a qualidade aromática desses vinhos.

\section{REFERÊNCIAS}

AMERINE, M.; OUGH, C.S. Análisis de vinos y mostos. Zaragoza: Acribia, 1976. 158p.

ANDERSON, M.M. et al. Viticultural evaluation of French and Californian Chardonnay clones grown for production of sparkling wine. American Journal of Enology and Viticulture, Davis, v.59, n.1, p.73-77, 2008.

BERTRAND, A. Recherches sur l'analyse des vins par chromatographie en phase gazeuse. 1975. 291f. Thèse (Doctorat d'État ès Sciences) - Institut d'Enologie, Université de Bordeaux II, Talence.

BRASIL. Ministério da Agricultura, Pecuária e Abastecimento. Portaria n. 283, de 18 de junho de 1998. Aprova normas e procedimentos para o registro de estabelecimento, bebidas e vinagres, inclusive vinhos e derivados da uva e do vinho e expedição dos respectivos certificados. Diário Oficial da República Federativa do Brasil. Brasília, DF, 22 jun. 1998. Seç̧ão 1, n.106.

FIDELIBUS, M.W. et al. Yield components and fruit composition of six Chardonnay grapevine clones in the Central San Joaquin Valley, California. American Journal of Enology and Viticulture, Davis, v.57, n.4, p.503-509, 2006.

MERCOSUL. Resolução 45/1996 do GMC. Regulamento Vitivinícola do Mercosul. In: IBRAVIN. Legislação vitivinícola. Bento Gonçalves: Ibravin, 2002.

PERKIN ELMER. Analytical methods for atomic absorption spectrophotometry. Singapura: Perkin Elmer, 2000. 300p.
RIBÉREAU-GAYON, P. et al. Traité d’Enologie: chimie du vin, stabilisation et traitements. Paris: Dunod, 1998. V.2, 519p.

RIBÉREAU-GAYON, P. et al. Traité d'CEnologie: sciences et techniques du vin: analyse et contrôle des vins. Paris: Dunod, 1982. V.1, 645p.

RIZZON, L.A. Composição química dos vinhos da Microrregião Homogênea Vinicultora de Caxias do Sul (MRH 311) - Compostos voláteis. Bento Gonçalves: Embrapa-CNPUV, 1987. 4p. (Embrapa-CNPUV. Comunicado Técnico, 5).

RIZZON, L.A. et al. Teores de prolina em vinhos brasileiros. In: CONGRESSO BRASILEIRO DE VITICULTURA E ENOLOGIA, 12., 1993, Bento Gonçalves. Anais... Bento Gonçalves: Embrapa Uva e Vinho, 1993. p.37-38.

RIZZON, L.A. et al. Discrimination of wines from the Mercosul countries according to their mineral composition. Journal International des Sciences de la Vigne et du Vin, Bordeaux, v.31, n.1, p.43-47, 1997.

RIZZON, L.A. et al. Teores de cátions dos vinhos da Serra Gaúcha. Ciência e Tecnologia de Alimentos, Campinas, v.28, n.3, p.635-641, 2008. Disponível em: <http:// www.scielo.br/pdf/cta/v28n3/a20v28n3.pdf>. Acesso em: 23 mar. 2009. doi: 10.1590/S0101-20612008000300020.

UVIBRA. Dados da vitivinicultura: quantidade de uvas processadas no Rio Grande do Sul. Bento Gonçalves: Embrapa Uva e Vinho, 2008. Online. Disponível em: http:// www.cnpuv.embrapa.br/prodserv/vitivinicultura. Acesso em: 16 fev. 2009.

WOLPERT, J.A. et al. Field performance of six Chardonnay clones in the Napa Valley. American Journal of Enology and Viticulture, Davis, v.45, n.4, p.393-400, 1994. 